\title{
Update on current and emerging treatment options for post-polio syndrome
}

This article was published in the following Dove Press journal:

Therapeutics and Clinical Risk Management

3 July 2010

Number of times this article has been viewed

\author{
Elisabeth Farbu \\ Neurocenter and National \\ Competence Center for Movement \\ Disorders, Stavanger University \\ Hospital, Stavanger, Norway
}

\begin{abstract}
Post-polio syndrome (PPS) refers to the clinical deterioration experienced by many polio survivors several decades after their acute illness. The symptoms are new muscle weakness, decreased muscle endurance, fatigue, muscle pain, joint pain, cold intolerance, and this typical clinical entity is reported from different parts of the world. The pathophysiology behind PPS is not fully understood, but a combination of distal degeneration of enlarged motor units caused by increased metabolic demands and the normal aging process, in addition to inflammatory mechanisms, are thought to be involved. There is no diagnostic test for PPS, and the diagnosis is based on a proper clinical workup where all other possible explanations for the new symptoms are ruled out. The basic principle of management of PPS lies in physical activity, individually tailored training programs, and lifestyle modification. Muscle weakness and muscle pain may be helped with specific training programs, in which training in warm water seems to be particularly helpful. Properly fitted orthoses can improve the biomechanical movement pattern and be energy-saving. Fatigue can be relieved with lifestyle changes, assistive devices, and training programs. Respiratory insufficiency can be controlled with noninvasive respiratory aids including biphasic positive pressure ventilators. Pharmacologic agents like prednisone, amantadine, pyridostigmine, and coenzyme Q10 are of no benefit in PPS. Intravenous immunoglobulin (IVIG) has been tried in three studies, all having positive results. IVIG could probably be a therapeutic alternative, but the potential benefit is modest, and some important questions are still unanswered, in particular to which patients this treatment is useful, the dose, and the therapeutic interval.
\end{abstract}

Keywords: polio, survivors, fatigue, aging, therapeutics

\section{Introduction}

Poliomyelitis (polio) occurs as a result of infection by the polio virus, which in $1 \%-2 \%$ of infected patients attacks the anterior horn in the spinal cord, leading to inflammation and possible cell death. After the introduction of the polio vaccines in the 1950s, the polio epidemics diminished rapidly in the industrialized world, but there are still areas in Asia and Africa where the virus is endemic and epidemics occur. Acute polio is no longer a constant threat to people in the polio-free areas of the world (Europe, the US, and the Pacific), but there are still thousands of polio survivors who are at risk of developing late manifestations of the disease. Even though the first report of new muscle weakness following recovery from acute paralytic poliomyelitis was published in $1875,{ }^{1}$ polio was long considered to be a three-phase illness, with muscle weakness followed by recovery, and then a life-long stable plateau phase. This paradigm was challenged when large groups of polio patients, who became ill
Correspondence: Elisabeth Farbu

Consultant Neurologist,

Department of Neurology,

Stavanger University Hospital, N-4068,

Stavanger, Norway

Fax +II 475 I5I 9916

Email elfa@sus.no 
in the epidemics of the 1940s and 1950s, reported clinical deterioration and a new condition several years after the acute illness. The symptoms were common to different polio populations all over the world, and as the reports were systematically recorded, the term "post-polio syndrome" (PPS) were coined in the 1980s, describing this new, late manifestation of polio after several years with stable function following initial recovery. ${ }^{2}$ Public awareness of this topic seems to be increasing, ${ }^{3}$ and the term PPS is now widely accepted.

The exact prevalence of PPS among polio survivors is not known, but studies have reported a PSS prevalence in $15 \%-80 \%$ of all patients with previous polio, depending on the criteria applied and population studied. ${ }^{4-10}$ The precise prevalence of PPS is therefore difficult to establish, and a genuine difference between different populations cannot be excluded. The prevalence in two US polio populations was $28.5 \%$ and $64 \%$, respectively. ${ }^{10,11}$ For European populations, one Dutch study reported a prevalence of late onset polio symptoms of $46 \%$, one study from Edinburgh reported a prevalence of more than $60 \%$, a prevalence of $52 \%$ has been reported in Estonia, with $60 \%$ for Norway, and $63 \%$ for Denmark. ${ }^{9,12-14}$

\section{Clinical features and diagnosis}

The major clinical features of PPS are new muscle weakness, new atrophy, muscle and joint pain, increased muscular fatigability, general fatigue, and cold intolerance. , $^{2,5,69,15,16}$ The diagnostic process for PPS is concentrated on a thorough clinical workup where all other possible neurologic, medical, orthopedic, and psychologic causes for the new deterioration are ruled out. There is no diagnostic test for PPS, and the diagnosis is based on clinical criteria. Several authors have proposed diagnostic criteria for PPS, $, 5,16,17$ where the March of Dimes (MoD) criteria seem to be more and more universally accepted. The MoD criteria also include that symptoms should persist for at least one year, illustrating the chronic course. The MoD criteria are as follows:

- Prior paralytic poliomyelitis with evidence of motor neuron loss, as confirmed by a history of the acute paralytic illness, signs of residual weakness, and atrophy of muscles on neurologic examination, and signs of denervation on electromyography.

- A period of partial or complete functional recovery after acute paralytic poliomyelitis, followed by an interval (usually 15 years or more) of stable neurologic function.
- Gradual or sudden onset of progressive and persistent muscle weakness or abnormal muscle fatigability (decreased endurance), with or without generalized fatigue, muscle atrophy, or muscle and joint pain. (Sudden onset may follow a period of inactivity, or trauma, or surgery). Less commonly, symptoms attributed to PPS include new problems with swallowing or breathing.

- Symptoms persisting for at least a year.

- Exclusion of other neurologic, medical, and orthopedic problems as causes of symptoms.

Widespread muscle weakness and female gender are considered to be the major risk factors for PPS. ${ }^{11}$ The new weakness or atrophy is usually asymmetric and limited to certain muscle groups, proximal or distal, either in previously weakened or presumably unaffected muscles. Electromyography may show subclinical involvement, with enlarged motor units in clinically unaffected muscles indicating a subclinical involvement during the acute illness. More than $50 \%$ of the motor neurons within one spinal cord segment must be destroyed before a weakness can be detected clinically. ${ }^{18}$ Ivanyi et al showed that a computed tomography (CT) scan of polio muscles may be helpful to explore the muscle abnormalities, and thereby supplying clinical and neurophysiologic examinations. ${ }^{19}$ Whether magnetic resonance imaging (MRI) can be helpful to detect anterior horn abnormalities in PPS remains to be investigated in future studies. Decreased muscle endurance and increased muscle fatigue is common, and may precede the weakness. A subtle first sign may be that the time needed for recovery after muscle activity increases, and muscle endurance slowly deteriorates. Whether generalized fatigue is primarily physiologic or multifactorial is debated, ${ }^{20-22}$ but it is important to bear in mind that this phenomenon is considered by many patients to be the most disabling symptom in their daily life.

Muscle pain is very common ${ }^{6}$ and appears to be due to overuse of weak muscles or disuse of other muscle groups compensating for weakened polio-affected muscles. Joint pain can be caused by joint instability, anisomelia (unequal length of limbs), disuse of muscles, abnormal biomechanical movements, and degenerative joint diseases. Scoliosis and kyphosis can lead to an unbalanced workload in the spine, leading to asymmetric degenerative changes and the risk of radiculopathies in the neck or lower back. Chest deformities also increase the risk of respiratory insufficiency, and excessive daytime sleepiness, sleep apnea, morning headache, and dyspnea are typical complaints from patients with polio-related respiratory problems. Bulbar muscles can 
also be affected (causing dysphagia, obstructive sleep apnea, dysarthria, or facial weakness), but symptoms from this level are not common. ${ }^{6,23-26}$

\section{Pathogenesis}

There is a consensus that the neuromuscular symptoms of PPS can be explained by loss of enlarged motor units, which can be up to 10 times the normal size. ${ }^{27}$ There is an ongoing denervation and reinnervation, but the reinnervation process has an upper limit where the reinnervation cannot compensate for the ongoing denervation, and loss of motor units takes place..$^{5,728,29}$ However, what disturbs the denervation-reinnervation equilibrium and causes peripheral denervation is still unclear. Different etiologies have been proposed, including persistence or reactivation of polio virus infection, normal aging process causing loss of motor neurons, increased metabolic demand in the motor neurons, inflammation at the spinal level, loss of muscle fibers or change in intrinsic properties within muscle fibers, and a combination of factors including overweight, disuse, overuse, and deconditioning. ${ }^{30-34}$

Research has not been able to verify a persistent polio virus infection or relation to PPS, and it seems unlikely that persistent poliovirus infection plays a role in the pathogenesis of PPS. ${ }^{35-37}$

When it comes to noninfectious inflammation at the spinal level, there are several observations that support this hypothesis, ie, perivascular inflammatory signs in the spinal cord with mononuclear cells, antibody responses in the cerebrospinal fluid (CSF), and increased levels of inflammatory cytokines in the CSF. ${ }^{33,38,39}$ A systemic inflammatory response has also been postulated. ${ }^{32,40}$ At this time, there seems to be robust evidence that inflammatory changes at the spinal cord level play a significant role in the pathogenesis, and they may serve as a target for therapeutic approaches. ${ }^{33,41-43}$

After the third decade, all healthy individuals lose both numbers of motor units and a degree of muscle strength as a part of the normal aging process. This will also occur for PPS patients, but they have a greater loss of both strength and motor units, ${ }^{27}$ and the clinical consequences may be greater than in healthy humans because more muscle fibers are denervated within one enlarged motor unit. ${ }^{27,34}$ The normal ageing process probably contributes to the loss of muscle strength, but does not explain all of the deterioration. In previously polio-affected muscles, Type 1 fibers dominate, and there is decreased capillary density and reduced oxidative capacity. ${ }^{44}$

\section{Treatment options Nonpharmacologic treatment}

The management of PPS is still based on rehabilitation schemes including lifestyle changes, physiotherapy, training programs, and avoidance of secondary complications. ${ }^{25,45}$ An important advance occurred when it was documented that nonfatiguing exercises improved muscle strength and prohibited further decline of PPS without any obvious harmful effects. Several clinical aspects can be modulated with physical activity, including generalized fatigue, improved muscle endurance, and muscle strength, and were identified after introduction of individually tailored training programs. There are multiple ways of performing physical activity, and isokinetic, isometric, and endurance muscle training are all effective, leading to less fatigue and improved muscle strength. ${ }^{46-51}$ No complications or side effects were reported in these studies, but emphasis on avoiding overuse, as well as intermittent workouts with sufficient rest between interval exercises has been mandatory. Training on alternate days to allow enough recovery and nonfatiguing exercises with short duration and submaximal workload are methods to avoid overuse and decline in muscle function. ${ }^{25}$ Because several training methods are effective, there should be good opportunities for individually tailored patient programs, where the pattern of muscle weakness and general health status are taken into account when adjusting the program. Until now, there have been no long-term studies exploring the effects of training, except for two open follow-up studies where a positive effect on fatigue and physical capacity was found up to one year after the intervention. ${ }^{52,53}$ It seems that training programs performed in a warm climate can result in a longer lasting effect compared with training schemes in a colder climate, ${ }^{54}$ but studies investigating the potential long-term benefits have not been reported.

Training in warm water reduces the stress on joints and muscles, and warm water may have an analgesic effect. Dynamic water exercises, not involving swimming, are a good alternative for patients with PPS, with positive effects on pain relief, improved cardiovascular conditioning, and increased subjective well-being. ${ }^{55}$

Weakening of bulbar muscles causing dysphagia, weakness of voice, and vocal changes have been reported among PPS patients, ${ }^{24,56-58}$ but bulbar symptoms are not among the most frequent features. Speech therapy and laryngeal muscle training under supervision by speech therapists are useful to improve bulbar muscle function. ${ }^{56}$

The risk of respiratory insufficiency should be considered, because it could lead to serious complications, including 
increased frequency of respiratory infections, hypercapnia, pulmonary arterial hypertension, and ultimately, cor pulmonale. For PPS patients, weakened respiratory muscles in addition to severe chest deformities, such as kyphoscoliosis, can cause respiratory insufficiency. Typical symptoms are daytime sleepiness, sleep apnea, morning headache, and dyspnea. Early introduction of noninvasive respiratory aids such as intermittent positive pressure ventilation or biphasic positive pressure ventilators via a mouthpiece or nasal application can stabilize the situation and prevent complications like chest infections, further respiratory decline, and invasive ventilatory aid (with tracheostoma), ${ }^{59,60}$ and can also improve exercise capacity. ${ }^{45,61}$ Today's ventilators are handy in size and user-friendly, which increases compliance. PPS patients with a tracheostoma and mechanical home ventilation are reported to have good quality of life despite severe physical disability. ${ }^{62}$ In line with other muscle training in PPS, respiratory muscle training is useful, including for patients already using an intermittent noninvasive respiratory aid. ${ }^{63}$ General measures like stopping smoking, mobilization of secretions, and cough assistance are beneficial, and should be followed in all cases with PPS-related respiratory insufficiency. ${ }^{45,60}$

A shift from metal braces to lightweight carbon orthoses can increase walking ability in polio patients with new weakness, ${ }^{45,64-66}$ and biomechanical analysis of the walking pattern can lead to optimal design of orthoses and improved function in the lower limbs. ${ }^{45,65,67}$

Frequent periods of rest, energy conservation, and work simplification skills are thought to be useful for patients with fatigue, ${ }^{68}$ and general lifestyle modifications including weight control, physical activity, adaptation to assistive devices, and modification of daily activities are always advocated to diminish the symptoms of fatigue.

\section{Pharmacologic agents available}

The findings of inflammatory markers in the serum and CSF from PPS patients have raised the questions of the degree to which inflammation is a part of the pathophysiology and if there could be a benefit from anti-inflammatory treatment. This issue was partly explored in the 1990s, when prednisone was tried in combination with amantadine. No positive effect on muscle strength and fatigue was detected. ${ }^{69,70}$ However, these trials included small numbers of patients, and only one was designed to include a statistical power analysis. Because long-term use of steroids is connected with unwanted side effects, including increased risk of diabetes, osteoporosis, and steroid-induced myopathy, other pharmacologic agents should probably be tried first in PPS, given that is is a chronic disorder.

Pyridostigmine has been investigated in two randomized controlled studies, but was found to be without benefit regarding fatigue, quality of life, and muscle strength. ${ }^{71,72}$ The same lack of benefit on fatigue was reported when modafinil (400 mg daily) was investigated in a controlled study, and was found to be no better than placebo. ${ }^{73} \mathrm{Lam}-$ otrigine has been tried in an open study (15 patients treated with 50-100 mg lamotrigine daily), where a positive effect on quality of life (Nottingham Health Profile), pain (visual analog scale), and fatigue (fatigue severity scale) was found after two and four weeks. ${ }^{74}$ Because this study was single-blinded and not placebo-controlled, a randomized controlled trial is needed to confirm the results. A small double-blind pilot study did not find any additional positive effect on muscle resistance training for patients taking 200 mg coenzyme Q10 daily. ${ }^{75}$

\section{Intravenous immunoglobulin}

Despite the increasing use of intravenous immunoglobulin (IVIG) in neurologic autoimmune disorders over the past three decades, the mechanisms for the clinical effects of this therapy are not well understood. IVIG is thought to have the potential to act via several mechanisms, including effects on expression and function of Fc-receptors, modulation of the activation and effector functions of B- and T-cells, the complement system, neutralization of pathogenic antibodies, and cytokine production. ${ }^{76}$

Gonzales et al were the first researchers to show that IVIG reduced CSF inflammatory cytokine levels in PPS patients, ${ }^{41}$ and this observation provided the rationale for trying IVIG as a therapy in PPS. IVIG is considered to have a more favorable side effect profile than long-term corticosteroids. Adverse reactions from IVIG are rare but severe, and include thromboembolic events (stroke, myocardial infarction, pulmonary embolism), particularly in patients with a pre-existing increased risk for thromboembolic disease, eg, diabetes and established arteriosclerosis. ${ }^{77}$ Patients with pre-existing renal disease are at risk of reversible renal tubular necrosis, and in patients with severe $\operatorname{IgA}$ deficiency there is an increased risk of anaphylaxis. ${ }^{78}$ More common, but self-limiting, mild reactions include infusion-related headache, chills, muscle pain, and low back pain, and these infusion-related reactions can sometimes be relieved by slowing the infusion rate. ${ }^{78}$ Despite the potentially serious side effects, occurring particularly in predisposed patients, IVIG is gener- 
ally considered to be a safe and effective first-line therapy for several autoimmune neurologic diseases, including Guillain Barré syndrome, chronic inflammatory demyelinating polyneuropathy, and exacerbations of myasthenia gravis. For patients with PPS, three studies have explored the effects of IVIG, comprising two controlled studies and one open study. A multicenter double-blind, randomized Swedish study included 135 patients in whom the primary endpoints were muscle strength in a pre-selected muscle group and quality of life (SF-36 scale). The patients were treated with either IVIG $90 \mathrm{~g}$ or placebo, repeated after three months. A significant difference on muscle strength was found, but there was no significant effect on quality of life or the secondary endpoints of pain, balance, and sleep quality. ${ }^{43}$

One smaller, randomized, controlled pilot study was performed in 20 patients by Farbu et al. ${ }^{79}$ The primary endpoints were muscle strength (isometric), pain (visual analog scale), and fatigue (fatigue severity scale) after three months. The patients were treated with one dose of IVIG ( $2 \mathrm{~g} / \mathrm{kg}$ body weight). A significant effect was found for pain, but not for muscle strength or fatigue. It was also found that the levels of the inflammatory cytokine, tumor necrosis factor, in the CSF were reduced after treatment. A further open study done in 14 patients explored the effect of $90 \mathrm{mg}$ IVIG on muscle strength, physical ability measured by a walking test, and quality of life (SF-36).$^{80}$ There was a positive effect on quality of life, but not on muscle strength or physical ability. These studies give a promising indication that IVIG probably is a treatment option to some patients with PPS, but it is not clear which patients would benefit from this therapy. The existing studies should be interpreted according to their methodologic limitations, in that they have not explored the long-term effects, optimal dose, or optimal therapy cycle, and the modest observed benefits. The use of IVIG in various neurologic disorders is expanding, but it has limited availability and comes at a very high cost. This calls for more investigation of PPS, to help distinguish between responders and nonresponders, long-term effects, dose, and treatment interval. A costbenefit analysis should also be performed. Gonzales et al recently published a paper where five possible proteins are suggested to be predictable biomarkers for PPS, ie, gelsolin, hemopexin, peptidylglycine alpha-amidating monooxygenase, glutathione synthetase, and kallikrein $6 .{ }^{42}$ These observations are important, and could lead to a new approach when confirming the diagnosis and developing new therapeutic strategies.
Conclusion

The primary treatment of PPS today is based on nonpharmacologic intervention, including individually tailored training programs and lifestyle modification. Prednisone, amantadine, pyridostigmine, and modafinil are of no benefit for these patients. However, novel research during the last decade has uncovered changes in the CSF which probably play a role in the pathogenesis. These changes can be targets for anti-inflammatory treatments, and IVIG has been tried with promising, albeit modest results. Before IVIG can be recommended as standard therapy, we need to undertake more research to detect the long-term effects of this treatment, and to identify patients who will benefit from the treatment (responders versus nonresponders), and we need to find the appropriate dose and proper treatment interval.

\section{Disclosure}

The author reports no conflict of interest in this work.

\section{References}

1. Raymond M. Paralysie essentielle de l'enfance, atrophie musculaire consecutive. Comptes Rendus Soc Bio. 1875;127:158-165.

2. Halstead LS, Rossi CD. New problems in old polio patients: Results of a survey of 539 polio survivors. Orthopedics. 1985;8(7):845-850.

3. Johnson K. For some survivors, polio won't fade into the past. $N Y$ Times. 2010 Feb 2. Available at: http://www.nytimes.com/2010/02/03/ health/03polio.html?ref=health Accessed Apr 24, 2010.

4. Burger H, Marincek C. The influence of post-polio syndrome on independence and life satisfaction. Disabil Rehabil. 2000;22(7): 318-322.

5. Dalakas MC. The post-polio syndrome as an evolved clinical entity. Definition and clinical description. Ann NY Acad Sci. 1995;753: 68-80.

6. Farbu E, RekandT, Gilhus NE. Post polio syndrome and total health status in a prospective hospital study. Eur J Neurol. 2003;10(4):407-413.

7. Halstead LS. Post-polio syndrome. Sci Am. 1998;278(4):42-47.

8. Halstead LS, Rossi CD. Post-polio syndrome: Clinical experience with 132 consecutive outpatients. Birth Defects Orig Artic Ser. 1987; 23(4):13-26.

9. Ivanyi B, Nollet F, Redekop WK, et al. Late onset polio sequelae: Disabilities and handicaps in a population-based cohort of the 1956 poliomyelitis outbreak in the Netherlands. Arch Phys Med Rehabil. 1999;80(6):687-690.

10. Ramlow J, Alexander M, LaPorte R, Kaufmann C, Kuller L. Epidemiology of the post-polio syndrome. Am J Epidemiol. 1992;136(7): 769-786.

11. Windebank AJ, Litchy WJ, Daube JR, Kurland LT, Codd MB, Iverson R. Late effects of paralytic poliomyelitis in Olmsted County, Minnesota. Neurology. 1991;41(4):501-507.

12. Lonnberg F. Late onset polio sequelae in Denmark. Results of a nationwide survey of 3,607 polio survivors. Scand J Rehabil Med Suppl. 1993;28:1-32.

13. Pentland B, Hellawell D, Benjamin J, Prasad R, Ainslie A. Survey of the late consequences of polio in Edinburgh and the Lothians. Health Bull (Edinb). 2000;58(4):267-275.

14. Rekand T, Korv J, Farbu E, et al. Long term outcome after poliomyelitis in different health and social conditions. J Epidemiol Community Health. 2003;57(5):368-372. 
15. Conde MT, Oliveira AS, Quadros AA, et al. Post-polio syndrome: Epidemiologic and prognostic aspects in Brazil. Acta Neurol Scand. 2009;120(3):191-197.

16. March of Dimes. Identifying Best Practices in Diagnosis and Care: White Plains, March of Dimes International Conference on Post Polio Syndrome; 2000.

17. Halstead LS. Assessment and differential diagnosis for post-polio syndrome. Orthopedics. 1991;14(11):1209.

18. Bodian D. Histopathologic basis of clinical findings in poliomyelitis. Am J Med. 1949;(6):563-578.

19. Ivanyi B, Redekop W, De Jongh R, De Visser M. Computed tomographic study of the skeletal musculature of the lower body in 45 postpolio patients. Muscle Nerve. 1998;21(4):540-542.

20. Ostlund G, Borg K, Wahlin A. Cognitive functioning in post-polio patients with and without general fatigue. J Rehabil Med. 2005; 37(3):147-151.

21. Ostlund G, Wahlin A, Sunnerhagen KS, Borg K. Vitality among Swedish patients with post-polio: A physiological phenomenon. J Rehabil Med. 2008;40(9):709-714.

22. Trojan DA, Arnold DL, Shapiro S, et al. Fatigue in post-poliomyelitis syndrome: Association with disease-related, behavioral, and psychosocial factors. PM R. 2009;1(5):442-449.

23. Howard RS, Wiles CM, Spencer GT. The late sequelae of poliomyelitis. QJ Med. 1988;66(251):219-232.

24. Ivanyi B, Phoa SS, de VM. Dysphagia in postpolio patients: A videofluorographic follow-up study. Dysphagia. 1994;9(2):96-98.

25. Jubelt B, Agre JC. Characteristics and management of postpolio syndrome. JAMA. 2000;284(4):412-414.

26. Kidd D, Howard RS, Williams AJ, Heatley FW, Panayiotopoulos CP, Spencer GT. Late functional deterioration following paralytic poliomyelitis. QJ Med. 1997;90(3):189-196.

27. Grimby G, Stalberg E, Sandberg A, Sunnerhagen KS. An 8-year longitudinal study of muscle strength, muscle fiber size, and dynamic electromyogram in individuals with late polio. Muscle Nerve. 1998;21(11):1428-1437.

28. Borg K. Post-Polio Muscle Dysfunction. 29th European Neuromuscular Centre Workshop. 1994 Oct 14-16. Naarden, The Netherlands. Neuromuscular Disorders. 1996;6(1):75-80.

29. Dalakas MC, Elder G, Halett M. A long-term follow-up study of patients with post-poliomyelitis neuromuscular symptoms. $N$ Engl J Med. 1986;314(15):959-963.

30. Colbere-Garapin F, Duncan G, Pavio N, Pelletier I, Petit I. An approach to understanding the mechanisms of poliovirus persistence in infected cells of neural or non-neural origin. Clin Diagn Virol. 1998; 9(2-3):107-113.

31. Dalakas MC. Pathogenetic mechanisms of post-polio syndrome: Morphological, electrophysiological, virological, and immunological correlations. Ann NY Acad Sci. 1995;753:167-185.

32. Fordyce CB, Gagne D, Jalili F, et al. Elevated serum inflammatory markers in post-poliomyelitis syndrome. J Neurol Sci. 2008;271(1-2):80-86.

33. Gonzalez H, Khademi M, Andersson M, Wallstrom E, Borg K, Olsson T. Prior poliomyelitis - evidence of cytokine production in the central nervous system. J Neurol Sci. 2002;205(1):9-13.

34. Stalberg E, Grimby G. Dynamic electromyography and muscle biopsy changes in a four-year follow-up: Study of patients with a history of polio. Muscle Nerve. 1995;18(7):699-707.

35. Melchers W, Zoll J, Van Kuppeveld F, Swanink C, Galama J. There is no evidence for persistent enterovirus infections in chronic medical conditions in humans. Rev Med Virol. 1994;4:235-243.

36. Roivainen M, Kinnunen E, Hovi T. Twenty-one patients with strictly defined postpoliomyelitis syndrome: No poliovirus-specific IgM antibodies in the cerebrospinal fluid. Ann Neurol. 1994;36(1):115-116.

37. Muir P, Nicholson F, Spencer GT, et al. Enterovirus infection of the central nervous system of humans: Lack of association with chronic neurological disease. J Gen Virol. 1996;77 (Pt 7):1469-1476.
38. Pezeshkpour GH, Dalakas MC. Pathology of spinal cord in postpoliomyelitis muscular atrophy. Birth Defects Orig Artic Ser. 1987; 23(4):229.

39. Sharief MK, Hentges R, Ciardi M. Intrathecal immune response in patients with the post-polio syndrome. $N$ Engl J Med. 1991;325(11): 749-755.

40. Ginsberg AH, Gale MJ Jr, Rose LM, Clark EA. T-cell alterations in late postpoliomyelitis. Arch Neurol 1989;46(5):497-501.

41. Gonzalez H, Khademi M, Andersson M, et al. Prior poliomyelitis-IVIg treatment reduces proinflammatory cytokine production. J Neuroimmunol. 2004;150(1-2):139-144.

42. Gonzalez H, Ottervald J, Nilsson KC, et al. Identification of novel candidate protein biomarkers for the post-polio syndrome-implications for diagnosis, neurodegeneration and neuroinflammation. J Proteomics. 2009;71(6):670-681.

43. Gonzalez H, Sunnerhagen KS, Sjoberg I, Kaponides G, Olsson T, Borg K. Intravenous immunoglobulin for post-polio syndrome: A randomised controlled trial. Lancet Neurol. 2006;5(6):493-500.

44. Borg K, Henriksson J. Prior poliomyelitis-reduced capillary supply and metabolic enzyme content in hypertrophic slow-twitch (type I) muscle fibres. J Neurol Neurosurg Psychiatry. 1991;54(3):236-240.

45. Farbu E, Gilhus NE, Barnes MP, et al. EFNS guideline on diagnosis and management of post-polio syndrome. Report of an EFNS task force. Eur J Neurol. 2006;13(8):795-801.

46. Agre JC, Rodriquez AA, Franke TM. Strength, endurance, and work capacity after muscle strengthening exercise in postpolio subjects. Arch Phys Med Rehabil. 1997;78(7):681-686.

47. Chan KM, Amirjani N, Sumrain M, Clarke A, Strohschein FJ. Randomized controlled trial of strength training in post-polio patients. Muscle Nerve. 2003;27(3):332-338.

48. Einarsson G. Muscle conditioning in late poliomyelitis. Arch Phys Med Rehabil. 1991;72(1):11-14.

49. Ernstoff B, Wetterqvist H, Kvist H, Grimby G. Endurance training effect on individuals with postpoliomyelitis. Arch Phys Med Rehabil. 1996;77(9):843-848.

50. Oncu J, Durmaz B, Karapolat H. Short-term effects of aerobic exercise on functional capacity, fatigue, and quality of life in patients with post-polio syndrome. Clin Rehabil. 2009;23(2):155-163.

51. Spector SA, Gordon PL, Yildiz E, Sivakumar K, Hurley BF, Dalakas MC. Effect of strength training in patients with post-polio syndrome. A preliminary report. Ann NY Acad Sci. 1995;753:402-404.

52. Bertelsen M, Broberg S, Madsen E. Outcome of physiotherapy as part of a multidisciplinary rehabilitation in an unselected polio population with one-year follow-up: An uncontrolled study. J Rehabil Med. 2009; 41(1):85-87.

53. Davidson AC, Auyeung V, Luff R, Holland M, Hodgkiss A, Weinman J. Prolonged benefit in post-polio syndrome from comprehensive rehabilitation: A pilot study. Disabil Rehabil. 2009;31(4):309-317.

54. Strumse YAS, Stanghelle JK, Utne L, Ahlvin P, Svendsby EK. Treatment of patients with postpolio syndrome in a warm climate. Disabil Rehabil. 2003;25(2):77-84.

55. Willen C, Sunnerhagen KS, Grimby G. Dynamic water exercise in individuals with late poliomyelitis. Arch Phys Med Rehabil. 2001;82(1):66-72.

56. Abaza MM, Sataloff RT, Hawkshaw MJ, Mandel S. Laryngeal manifestations of postpoliomyelitis syndrome. J Voice. 2001;15(2):291-294.

57. Driscoll BP, Gracco C, Coelho C, et al. Laryngeal function in postpolio patients. Laryngoscope. 1995;105(1):35-41.

58. Sonies BC, Dalakas MC. Dysphagia in patients with the post-polio syndrome. N Engl J Med. 1991;324(17):1162-1167.

59. Bach JR. Management of post-polio respiratory sequelae. Ann NY Acad Sci. 1995;753:96-102.

60. Bergholtz B, Mollestad SO, Refsum H. Post-polio respiratory failure. New manifestations of a forgotten disease. Tidsskr Nor Laegeforen. 1988;108(29):2474-2475. 
61. Vaz Fragoso CA, Kacmarek RM, Systrom DM. Improvement in exercise capacity after nocturnal positive pressure ventilation and tracheostomy in a postpoliomyelitis patient. Chest. 1992;101(1):254-257.

62. Markstrom A, Sundell K, Lysdahl M, Andersson G, Schedin U, Klang B. Quality-of-life evaluation of patients with neuromuscular and skeletal diseases treated with noninvasive and invasive home mechanical ventilation. Chest. 2002;122(5):1695-1700.

63. Klefbeck B, Lagerstrand L, Mattsson E. Inspiratory muscle training in patients with prior polio who use part-time assisted ventilation. Arch Phys Med Rehabil. 2000;81(8):1065-1071.

64. Heim M, Yaacobi E, Azaria M. A pilot study to determine the efficiency of lightweight carbon fibre orthoses in the management of patients suffering from post-poliomyelitis syndrome. Clin Rehabil. 1997; 11(4):302-305.

65. Brehm MA, Beelen A, Doorenbosch CA, Harlaar J, Nollet F. Effect of carbon-composite knee-ankle-foot orthoses on walking efficiency and gait in former polio patients. J Rehabil Med. 2007;39(8):651-657.

66. Hachisuka K, Makino K, Wada F, Saeki S, Yoshimoto N, Arai M. Clinical application of carbon fibre reinforced plastic leg orthosis for polio survivors and its advantages and disadvantages. Prosthet Orthot Int 2006;30(2):129-135.

67. Perry J, Clark D. Biomechanical abnormalities of post-polio patients and the implications for orthotic management. Neurorehabilitation. 1997;8(2):119-138.

68. Packer TL, Martins I, Krefting L, Brouwer B. Activity and post-polio fatigue. Orthopedics. 1991;14(11):1223-1226.

69. Dinsmore S, Dambrosia J, Dalakas MC.A double-blind, placebo-controlled trial of high-dose prednisone for the treatment of post-poliomyelitis syndrome. Ann NY Acad Sci. 1995;753:303-313.

70. Stein DP, Dambrosia JM, Dalakas MC. A double-blind, placebocontrolled trial of amantadine for the treatment of fatigue in patients with the post-polio syndrome. Ann NY Acad Sci. 1995;753:296-302.

71. Horemans HLD, Nollet F, Beelen A, et al. Pyridostigmine in postpolio syndrome: No decline in fatigue and limited functional improvement. J Neurol Neurosurg Psychiatry. 2003;74(12):1655-1661.
72. Trojan DA, Collet JP, Shapiro S, et al. A multicenter, randomized, double-blinded trial of pyridostigmine in postpolio syndrome. Neurology. 1999;53(6):1225-1233.

73. Vasconcelos OM, Prokhorenko OA, Salajegheh MK, et al. Modafinil for treatment of fatigue in post-polio syndrome: A randomized controlled trial. Neurology. 2007;68(20):1680-1686.

74. On AY, Oncu J, Uludag B, Ertekin C. Effects of lamotrigine on the symptoms and life qualities of patients with post polio syndrome: A randomized, controlled study. NeuroRehabilitation. 2005;20(4): $245-251$.

75. Skough K, Krossen C, Heiwe S, Theorell H, Borg K. Effects of resistance training in combination with coenzyme Q10 supplementation in patients with post-polio: A pilot study. J Rehabil Med. 2008;40(9):773-775.

76. Elovaara I, Apostolski S, van Doorn P, et al. EFNS guidelines for the use of intravenous immunoglobulin in treatment of neurological diseases: EFNS task force on the use of intravenous immunoglobulin in treatment of neurological diseases. Eur J Neurol. 2008;15(9):893-908.

77. Vucic S, Chong PS, Dawson KT, Cudkowicz M, Cros D. Thromboembolic complications of intravenous immunoglobulin treatment. Eur Neurol. 2004;52(3):141-144.

78. Dalakas MC. Intravenous immunoglobulin in autoimmune neuromuscular diseases. JAMA. 2004;291(19):2367-2375.

79. Farbu E, Rekand T, Vik-Mo E, Lygren H, Gilhus NE, Aarli JA. Post-polio syndrome patients treated with intravenous immunoglobulin: A double-blinded randomized controlled pilot study. Eur J Neurol. 2007;14(1):60-65.

80. Kaponides G, Gonzalez H, Olsson T, Borg K. Effect of intravenous immunoglobulin in patients with post-polio syndrome - an uncontrolled pilot study. J Rehabil Med. 2006;38(2):138-140.
Therapeutics and Clinical Risk Management

\section{Publish your work in this journal}

Therapeutics and Clinical Risk Management is an international, peerreviewed journal of clinical therapeutics and risk management, focusing on concise rapid reporting of clinical studies in all therapeutic areas, outcomes, safety, and programs for the effective, safe, and sustained use of medicines. This journal is indexed on PubMed Central, CAS,

\section{Dovepress}

EMBase, Scopus and the Elsevier Bibliographic databases. The manuscript management system is completely online and includes a very quick and fair peer-review system, which is all easy to use. Visit http://www.dovepress.com/testimonials.php to read real quotes from published authors. 